\title{
Динамика содержания пигментов в листья тополя черного (Populus nigra L.), растущего около автодорог в г. Бийске
}

\section{Dynamics of pigments concentration in the black poplar leaves (Populus nigra L.) growing near the auto road in Biysk}

\author{
Соколова Г. Г., Калгина М. В. \\ Sokolova G. G., Kalgina M. V. \\ Алтайский государственный университет, г. Барнаул, Россия.E-mail: sokolova-gg@mail.ru,mariya.kalgina1@mail.ru \\ Altai State University, Barnaul, Russia
}

Peфepam. В статье приводятся результаты исследования содержания пигментов в листьях тополя черного, растущего вдоль автодорог в г. Бийске. Увеличение техногенного загрязнения способствует изменению количества и соотношения основных и дополнительных пигментов. По сравнению с контролем выявлено закономерное снижение содержания хлорофилла $а$ в листьях тополей, растущих на перекрестках и вдоль дорог, на 32-62 \%. Отмечено достоверное увеличение содержания хлорофилла $b$ на 14-41 \% и каротиноидов на 8-29 \%, снижение отношения хлорофиллов $a / b$.

Ключевые слова. Автодороги, загрязнение, каротиноиды, листья тополя, хлорофилл $a$, хлорофилл $b$.

Summary. The article presents the results of the study of the content of pigments in the leaves of black poplar growing along the highways in Biysk. The increase in technogenic pollution contributes to the change in the amount and ratio of basic and additional pigments. Compared with the control, a logical decrease in the content of chlorophyll $a$ in the leaves of poplars growing on the crossroads and along roads by $32-62 \%$ was revealed. There was a significant increase in the content of chlorophyll $b$ by $14-41 \%$ and carotenoids by $8-29 \%$, a decrease in the ratio of chlorophylls $a / b$.

Keywords. Highways, chlorophyll $a$, chlorophyll $b$, carotenoids, the poplar leaves, pollution.

\section{Введение}

Фотосинтез является неотъемлемым процессом жизнедеятельности растений. Основными фотосинтетическими пигментами растений являются хлорофилл $a$, хлорофилл $b$ и каротиноиды. Преобладающим пигментом является хлорофилл $a$, выполняющий следующие важные функции: избирательное поглощение энергии света, запасание полученной энергии и преобразование ее фотохимическим путем в химическую энергию первичных фотовосстановленных и фотоокисленных соединений (Титова, 2010). Хлорофилл $b$ и каротиноиды являются вспомогательными фотосинтетическими пигментами, они выполнятся роль защитников и дополнительных соединений. В норме соотношение хлорофиллов $a$ и $b$ и каротиноидов составляет примерно 5:3:2, что считается наиболее оптимальным для эффективного протекания фотосинтезы (Павлова и др., 2010).

В условиях хронического загрязнения окружающей среды изменяется содержание и соотношение пигментов: снижается количество хлорофилла $a$, возрастает суммарное количество пигментов, и содержание вспомогательных пигментов (каротиноидов и антоцианов) возрастает. Такое приспособление растений рассматривается как адаптация ассимиляционного аппарата на стресс (Бухарина, Кузьмин, 2013; Алиева, 2014; Овечкина, Шаяхметова, 2015). Содержание фотосинтетических пигментов и их соотношение служат критериями функционального состояния древесных растений в условиях техногенного загрязнения и индикаторами экологического состояния окружающей среды (Зубарева и др., 2011). 
Основными источниками загрязнения атмосферного воздуха в г. Бийске является автотранспорт. Ведущими веществами, загрязняющими атмосферу в г. Бийске, являются пыль, сажа, диоксид азота, формальдегид, пыль, бензапирен и др. Эти соединения в значительной степени влияют на пигменты, разрушают хлорофилл $a$, изменяют соотношение основных и дополнительных фотосинтетических пигментов.

Тополь чёрный относится к числу наиболее распространённых видов древесных растений, применяемых в озеленении населённых пунктов. В условиях городов он проявляет довольно высокую устойчивость к загрязнению воздушного бассейна пылью, дымом и газообразными веществами. Одно дерево выделяет столько кислорода, сколько 7 елей, 4 сосны или 3 липы; за вегетативный сезон один тополь освобождает атмосферу от 20-30 кг пыли или сажи (Деревья, 2004).

Целью нашей работы явилось изучение динамики содержания фотосинтезирующих пигментов в листьях тополя черного (Populus nigra L.), растущего вдоль автодорог в г. Бийске.

\section{Материалы и методы}

Для оценки содержания фотосинтетических пигментов в листья тополя нами были заложены пробные площадки, расположенные вдоль автодорог в различных районах г. Бийска. Всего было заложено 8 пробных площадок: контроль, перекресток Толстого-Кирова, перекресток Ленина-Коммунарский, перекресток Социалистическая-Разина, перекресток Социалистическая-Кутузова, перекресток Мерлина-Митрофанова, ул. Трофимова, улица Советская. В границах пробной площадки выбиралось не менее 10 деревьев, с которых собирались здоровые, неповрежденные листья в нижней части кроны на уровне человеческого роста в количестве 100 шт. Сбор листьев осуществлялся в летний период 2017-2018 гг.

Измерение содержания фотосинтетических пигментов в листьях древесных растений проводилось с помощью спектрофотометра марки SHIMADZU UV-1800 в лаборатории кафедры экологии, биохимии и биотехнологии Алтайского государственного университета. Измерения максимумов поглощения пигментов проводились в трехкратной повторности на длине волн фотосинтетических пигментов: 662 нм - хлорофилл $a, 644$ нм - хлорофилл $b, 440,5$ нм - каротиноиды. Концентрации пигментов в листьях тополя рассчитывались в два этапа по формулам (Гулиев и др., 2009; Рогожин, 2013):

1 этап. Расчет концентрации пигментов листьев в спиртовом растворе (мг/л):

$\mathrm{C}_{a}=9,784 \mathrm{D}_{662}-0,99 \mathrm{D}_{644}$

$\mathrm{C}_{b}=21,426 \mathrm{D}_{644}-4,650 \mathrm{D}_{662}$,

$\mathrm{C}_{a}+\mathrm{C}_{b}=5,134 \mathrm{D}_{662}+20,436 \mathrm{D}_{664}$,

$\mathrm{C}_{k}=4,695 \mathrm{D}_{440,5}-9,268\left(\mathrm{C}_{a}-\mathrm{C}_{b}\right)$

где $\mathrm{D}_{662}, \mathrm{D}_{644}$ и $\mathrm{D}_{440,5}$ - оптическая плотность при длинах волн $662,644,440,5$ нм соответственно; $\mathrm{C}_{a}, \mathrm{C}_{b}, \mathrm{C}_{\kappa}-$ концентрация хлорофилла $a$, хлорофилла $b$ и каротиноидов в листьях объектов исследования (мГ/л).

2 этап. Расчет количества пигментов в пробе (мг/100 г):

$\mathrm{C}_{\mathrm{o}}=\mathrm{C} \cdot \mathrm{V} \cdot \mathrm{V} 2 / \mathrm{m} \cdot \mathrm{V} 1 \cdot 10$,

где C - концентрация пигмента, мг/л; V - объем исходной вытяжки, мл; V1 - объем вытяжки, взятой для разбавления, мл; V2 - объем разбавленной вытяжки, мл; $\mathrm{m}$ - масса навески. кин, 1990).

Полученные данные обработаны статистически с использованием t-критерия Стьюдента (Ла-

\section{Результаты и обсуждение}

Анализ содержания пигментов в листьях тополя черного, используемого для озеленения г. Бийска, выявил следующие закономерности.

Хлорофилл $\boldsymbol{a}$. На контроле содержание хлорофилла $a$ в листьях тополей варьировало от 5,22 до 4,89 мг/100 г, существенных изменений концентрации данного пигмента на протяжении летних ме- 
сяцев не отмечалось. Содержание хлорофилла $a$ в листьях тополей, растущих на перекрестках и вдоль автодорог, изменялось от 1,85 до 3,68 мг/100 г, что достоверно ниже по сравнению с контролем на $32-$ $62 \%$ (табл. 1). Наименьшее снижение концентрации хлорофилла $a$ отмечено в листьях тополей, растущих по улице Трофимова, наибольшее - в листьях тополей, растущих на перекрестках Ленина-Коммунарский и Мерлина-Митрофанова. В динамике по месяцам во всех точках выявлено небольшое увеличение содержания хлорофилла $a$ в июле и снижение в августе.

На листьях тополей, растущих вдоль дорог и на перекрестках, наблюдались некрозы, доля которых росла в течение летних месяцев. Особенно большой процент листьев с некрозами отмечен у тополей, растущих на перекрестках.

Таблица 1

Динамика содержания хлорофилла $a$ в листьях тополей, растущих вдоль автодорог и на перекрестках г. Бийска

\begin{tabular}{|l|c|c|c|}
\hline \multirow{2}{*}{ Точки отбора проб } & \multicolumn{3}{c|}{ Содержание хлорофилла $a$ мг/100 г } \\
\cline { 2 - 4 } & июнь & июль & Август \\
\hline Контроль & $5,22 \pm 0,05$ & $5,48 \pm 0,09$ & $4,89 \pm 0,08$ \\
\hline ул. Трофимова & $3,29 \pm 0,05$ & $3,68 \pm 0,08$ & $2,90 \pm 0,04$ \\
\hline Перекресток Социалистическая-Разина & $2,87 \pm 0,06$ & $3,46 \pm 0,03$ & $2,25 \pm 0,07$ \\
\hline Перекресток Толстого-Кирова & $2,84 \pm 0,04$ & $2,92 \pm 0,08$ & $2,04 \pm 0,09$ \\
\hline Перекресток Социалистическая-Кутузова & $2,71 \pm 0,06$ & $3,55 \pm 0,04$ & $2,15 \pm 0,05$ \\
\hline ул. Советская & $2,63 \pm 0,09$ & $3,15 \pm 0,07$ & $2,00 \pm 0,03$ \\
\hline Перекресток Ленина-Коммунарский & $2,59 \pm 0,09$ & $3,24 \pm 0,08$ & $1,85 \pm 0,05$ \\
\hline Перекресток Мерлина-Митрофанова & $2,56 \pm 0,08$ & $3,11 \pm 0,05$ & $1,99 \pm 0,08$ \\
\hline
\end{tabular}

Примечание: $\mathbf{3 , 2 9} \pm \mathbf{0 , 0 5}$ - значение достоверно при $\mathrm{p} \leq 0,05$.

Хлорофилл $\boldsymbol{b}$. Содержание хлорофилла $b$ в листьях тополей, растущих на контрольном участке, варьировало от 4,89 до 5,48 мг/100 г. В динамике по месяцам отмечено незначительное увеличение содержания хлорофилла $b$ в июле и снижение содержания хлорофилла $b$ в августе.

Содержание хлорофилла $b$ в листьях тополей, растущих на перекрестках и вдоль автодорог, изменялось от 1,25 до 2,44 мг/100 г, что достоверно выше по сравнению с контролем на 3-34 \% (табл. 2). Более высокое содержание исследуемого пигмента наблюдалось в листьях тополей, растущих на перекрестке Ленина-Коммунарский и Социалистическая-Кутузова, более низкое содержание - в листьях тополей, растущих по улице Трофимова. В динамике по месяцам достоверных изменений содержания хлорофилла $b$ выявлено не было.

Таблица 2

Динамика содержания хлорофилла $b$ в листьях тополей, растущих вдоль автодорог и на перекрестках г. Бийска

\begin{tabular}{|l|c|c|c|}
\hline \multirow{2}{*}{ Точки отбора проб } & \multicolumn{3}{c|}{ Содержание хлорофилла $b$, мг/100 г } \\
\cline { 2 - 4 } & июнь & июль & Август \\
\hline Контроль & $1,48 \pm 0,08$ & $1,61 \pm 0,06$ & $1,30 \pm 0,08$ \\
\hline Перекресток Ленина-Коммунарский & $2,38 \pm 0,07$ & $2,44 \pm 0,08$ & $1,45 \pm 0,08$ \\
\hline Перекресток Социалистическая-Кутузова & $2,28 \pm 0,05$ & $2,33 \pm 0,06$ & $1,42 \pm 0,05$ \\
\hline ул. Советская & $\mathbf{1 , 9 8} \pm \mathbf{0 , 0 4}$ & $\mathbf{2 , 1 5} \pm \mathbf{0 , 0 4}$ & $1,28 \pm 0,07$ \\
\hline ул. Трофимова & $1,87 \pm 0,08$ & $1,93 \pm 0,06$ & $2,00 \pm 0,06$ \\
\hline Перекресток Толстого-Кирова & $\mathbf{1 , 8 0} \pm \mathbf{0 , 0 4}$ & $\mathbf{1 , 9 2} \pm \mathbf{0 , 0 8}$ & $1,25 \pm 0,09$ \\
\hline Перекресток Социалистическая-Разина & $1,73 \pm 0,04$ & $1,79 \pm 0,03$ & $1,46 \pm 0,07$ \\
\hline Перекресток Мерлина-Митрофанова & $\mathbf{1 , 6 6} \pm \mathbf{0 , 0 6}$ & $1,74 \pm 0,09$ & $1,31 \pm 0,04$ \\
\hline
\end{tabular}

Примечание: $\mathbf{2 , 3 8} \pm \mathbf{0 , 0 7}-$ значение достоверно при $\mathrm{p} \leq 0,05$. 
Отношение хлорофиллов $\boldsymbol{a} / \boldsymbol{b}$. Отношение хлорофиллов $a / b$ в листьях тополей, растущих на контрольном участке, изменялось от 3,4 до 3,76 . Отношение хлорофиллов $a / b$ в листьях тополей, растущих на перекрестках и вдоль автодорог г. Бийска, было ниже по сравнению с контролем во всех точках. Наибольшие значения отношения хлорофиллов $a / b$ отмечены в листьях тополей, растущих по улице Трофимова, наименьшие - в листьях тополей, растущих на перекрестках Социалистическая-Разина и Ленина-Коммунарский (табл. 3).

Таблица 3

Отношение хлорофиллов $a / b$ в листьях тополей, растущих вдоль автодорог и на перекрестках г. Бийска

\begin{tabular}{|l|c|c|c|}
\hline \multirow{2}{*}{\multicolumn{1}{|c|}{ Точки отбора проб }} & \multicolumn{3}{c|}{ Отношение хлорофиллов $a / b$} \\
\cline { 2 - 4 } & июнь & июль & Август \\
\hline Контроль & 3,53 & 3,40 & 3,76 \\
\hline ул. Трофимова & 1,76 & 1,91 & 1,45 \\
\hline Перекресток Социалистическая-Разина & 1,66 & 1,93 & 1,54 \\
\hline Перекресток Толстого-Кирова & 1,58 & 1,52 & 1,63 \\
\hline Перекресток Мерлина-Митрофанова & 1,54 & 1,79 & 1,52 \\
\hline ул. Советская & 1,32 & 1,46 & 1,56 \\
\hline Перекресток Социалистическая-Кутузова & 1,19 & 1,52 & 1,51 \\
\hline Перекресток Ленина-Коммунарский & 1,09 & 1,33 & 1,27 \\
\hline
\end{tabular}

Каротиноиды. Содержание каротиноидов в листьях тополей, растущих на контрольном участке, варьировало от 0,83 до 0,94 мг/100 г. В динамике по месяцам достоверных изменений выявлено не было. Концентрация каротиноидов в листьях тополей, растущих вдоль автодорог и на перекрестках г. Бийска, изменялась от 1,31 до 1,79 мг/100 г, что достоверно выше по сравнению с контролем на 36 47 \% (табл. 4). Наибольшее содержание каротинодов отмечено в листьях тополей, растущих по улице Советской и на перекрестках Ленина-Коммунарский и Социалистическая-Кутузова (табл. 2, 3). В динамике по месяцам значительных, достоверных изменений по всем исследуемым точкам не выявлено.

Таблица 4

Динамика содержания каротиноидов в листьях тополей, растущих вдоль автодорог и на перекрестках г. Бийска

\begin{tabular}{|l|c|c|c|}
\hline \multirow{2}{*}{ Точки отбора проб } & \multicolumn{3}{c|}{ Содержание каротиноидов, мг/100 г } \\
\cline { 2 - 4 } & июнь & июль & Август \\
\hline Контроль & $0,83 \pm 0,08$ & $0,90 \pm 0,08$ & $0,94 \pm 0,03$ \\
\hline Ул. Советская & $1,64 \pm 0,05$ & $1,71 \pm 0,09$ & $1,79 \pm 0,03$ \\
\hline Перекресток Ленина-Коммунарский & $1,55 \pm 0,09$ & $1,67 \pm 0,06$ & $1,63 \pm 0,04$ \\
\hline Перекресток Социалистическая-Кутузова & $1,50 \pm 0,07$ & $1,58 \pm 0,91$ & $1,67 \pm 0,06$ \\
\hline Перекресток Толстого-Кирова & $1,48 \pm 0,05$ & $1,55 \pm 0,09$ & $1,60 \pm 0,02$ \\
\hline Ул. Трофимова & $1,46 \pm 0,04$ & $1,52 \pm 0,08$ & $1,59 \pm 0,02$ \\
\hline Перекресток Мерлина-Митрофанова & $1,37 \pm 0,09$ & $1,41 \pm 0,05$ & $1,48 \pm 0,05$ \\
\hline Перекресток Социалистическая-Разина & $1,31 \pm 0,06$ & $1,43 \pm 0,08$ & $1,52 \pm 0,08$ \\
\hline
\end{tabular}

Примечание: $\mathbf{1 , 6 4} \pm \mathbf{0 , 9 5}$ - значение достоверно при $\mathrm{p} \leq 0,05$.

Таким образом, содержание фотосинтезирующих пигментов в листьях тополей в г. Бийске зависит от места произрастания и уровня загрязнения. Под действием загрязняющих веществ хлорофилл $a$ разрушается, либо ускоряется его переход в форму хлорофилла $b$; при этом увеличивается содержание последнего, что подтверждается и литературными данными (Цандекова, Неверова, 2010; Овечкина, 
Шаяхметова, 2015 и др.). Увеличение содержания хлорофилла $b$ является адаптационным процессом. Концентрация его варьирует меньше по сравнению с содержанием хлорофилла $a$, что свидетельствует о большей устойчивости молекула хлорофилла $b$ к загрязняющим веществам.

Достоверное увеличение содержание каротиноидов по сравнению с контролем также является адаптивной реакцией на стрессовую нагрузку на организм растений в виде техногенного загрязнения.

\section{ЛИТЕРАТУРА}

Алиева М. Ю. Изучение параметров флуоресценции хлорофилла древесных растений в условиях различной транспортной нагрузки // Известия Самарского научного центра Российской академии наук, 2014. - № 1. - С. 701-703.

Бухарина И. Л., Кузьмин П. А. Влияние техногенной среды на жизненное состояние и содержание танинов в листьях древесных растений (на примере города Набережные Челны) // Вестник Поволжского государственного технологического университета, 2013. - № 1. - С. 72-79.

Гулиев Р. Б., Азизов Б. М., Абассзаде А. А. Оценка содержания хлорофилла в растениях, подвернутых антропогенному воздействию, спектрофотометрическим методом // Оптика и спектроскопия, 2009. - Т. 106. - № 3. - С. $514-517$

Деревья. - М: Астрель, 2004. - 319 с.

Зубарева К. Э. Качкин К. В., Сиромля Т. И. Влияние выбросов автомобильного транспорта на элементный состав листьев подорожника большого //Химия растительного сырья, 2011. - № 2. - С. 159-164.

Лакин Г. Ф. Биометрия. - М.: Высшая школа, 1990. - С. 350-352.

Овечкина E. С., Шаяххметова Р. И. Влияние антропогенных факторов на содержание пигментов сосны обыкновенной в летне-зимний период на территории Нижневартовского района // Известия Самарского научного центра Российской академии наук, 2015. - № 6. - С. 236-241.

Павлова Л. М., Котельникова И. М., Куимова Н. Г. Состояние фотосинтетических пигментов в вегетативных органах древесных растений в городской среде // Экология урбанизированных территорий, 2010 . - № 2. - С. 98-105.

Рогожин В. В. Практикум по биохимии. - СПб.: Лань, 2013. - С. 344-356.

Tumoвa M. C. Реакция пигментной системы сосны обыкновенной (Pinus sylvestris L.). На загрязнение окружающей среды // Вестник Красноярского государственного аграрного университета, 2013. - №10. - С. 122-126.

Цандекова О. Н., Неверова О. А. Влияние выбросов автотранспорта на пигментный комплекс листьев древесных растений // Известия Самарского научного центра РАН, 2010. - № 1. - С. 853-856. 